\title{
Sputtering and Implantation of VV-6025X Surface with Slow Heavy Ions Monitored with PIXE
}

\author{
M. Antoszewska*, J. Balcerski, R. Brzozowski, K. Dolecki, E. Frątczak, \\ T. GwizdaŁŁa, B. PawŁowski, M. Moneta \\ University of Łódź, Faculty of Physics and Applied Informatics, Pomorska 149, 90-236 Łódź, Poland
}

\begin{abstract}
In this work the characteristic radiation, emitted during interaction of medium energy (200 keV) ambient heavy ions (Ar) with $\mathrm{Fe}_{4} \mathrm{Co}_{66} \mathrm{Si}_{12} \mathrm{~B}_{14} \mathrm{Nb}_{1} \mathrm{Mo}_{2} \mathrm{Cu}_{1}$ (VV-6025X) amorphous alloy, was measured in grazing incident-exit angle geometry and in time sequence, in order to determine dynamics of formation of subsurface region, damaged through implantation, sputtering and interface mixing. It was shown that structure and composition of surface is unstable against heavy ions irradiation due to preferential sputtering and implantation of ions, and recoils, and that the dynamics of such modification can be monitored in-situ with particle induced $X$-ray emission (PIXE) method.
\end{abstract}

DOI: 10.12693/APhysPolA.126.136

PACS: 34.35.+a, 61.80.Lj

\section{Introduction}

Impact of heavy ions (HI) on surface of multicomponent material results in implantation of beam ions, preferential sputtering of surface elements and selective implantation of recoils, thus changing the initial composition of the surface [1]. Extensive kinematic mixing of the surface and interfaces, combined with local thermal heating, caused by the energy deposited in the surface by the stopping HI [2], can be observed. These phenomena determine structural transformations of the materials and influence their electric and magnetic properties [3-5].

Particle Induced $X$-rays Emission (PIXE) is one of the methods which can give an insight into these processes [6-8]. It is based on the analysis of characteristic $X$-rays emitted during the impact of HI with the surface, which provide not only fundamental information on atomic excitation and further recombination processes, but can also give practical information on elemental composition and dynamics of restructuration of the films and subsurface region, measured at the time of irradiation [7-8].

Because PIXE is accompanied and superimposed by continuous radiation coming from accelerated electrons and by other recombination and emission processes, the grazing incidence-exit geometry was used in order to suppress bremsstrahlung and the response from the deeper regions.

We show how to use PIXE to determine the dynamics of composition change for multicomponent amorphous alloys, subjected to prolonged irradiation with ambient HI.

\section{Experimental setup}

The Ar ions beams were accelerated by $300 \mathrm{kV}$ Cockroft-Walton accelerator of the Department of Solid State Physics to an energy of $230 \mathrm{keV}$. After leaving the acceleration tube, the beam was magnetically analyzed.

*corresponding author; e-mail: m_ateno@interia.pl
Ion beam current density on the sample, measured by the Faraday cup, was about $0.5 \mu \mathrm{A} / \mathrm{cm}^{2}$. $20 \mu \mathrm{m}$ thick $6025 \mathrm{X}$ foils, after surface cleaning with Ar ion sputtering, were transferred through air to reaction chamber of $10^{-6} \mathrm{hPa}$, fixed on $\mathrm{LN}_{2}$ cryostat and irradiated with $\mathrm{Ar}$ ions at various doses. Targets were mounted on a two axis goniometer in double alignment geometry: the incident grazing angle was fixed at at $\varphi_{\text {in }}<5^{\circ}$ and the exit grazing angle was fixed at $\varphi_{\text {out }}<5^{\circ}$, after preliminary measurements minimizing the signal from Si background. Ions RBS-scattered from the surface were registered at $90^{\circ}$ off the ion beam direction by a $\mathrm{Si}(\mathrm{Li})$ detector, cooled down to $c a-70^{\circ} \mathrm{C}$. PIXE $X$-rays spectra, emitted at $90^{\circ}$ off ion beam direction, were measured with Amptek SDD spectrometer [9] (active area $\left.25 \mathrm{~mm}^{2}, \mathrm{fwhm}=120 \mathrm{eV} @ 6.4 \mathrm{keV}\right)$, placed behind a $25 \mu \mathrm{m}$ kapton window and de-convoluted with XRF-FP and GuPIX [9, 10].

\section{Results and discussion}

Simulations of the experiment, performed with SRIM [11] showed for instance, that in the grazing incidence geometry, a $250 \mathrm{keV}$ Ar ion can sputter about $30 \mathrm{Fe}$ atoms (and the same amount of Au atoms). About $55 \%$ of incident Ar ions are scattered back above the Fe surface.

If an incident fluence of $10^{15} \mathrm{Ar} / \mathrm{cm}^{2}$ at $\varphi_{i n}=5^{\circ}$ is assumed, a $3 \mathrm{~nm}$ thick layer will be sputtered from the Fe surface.

This should be compared with penetration depth of $40 \mathrm{~nm}$ and projected range of $100 \mathrm{~nm}$ of Ar ions in Fe. This means that in this geometry the measured radiation is emitted mainly from the excited target atoms, leaving the surface, and from the incident ions backscattered in an excited state. The remaining part of incident ions, travelling in surface layer and initializing cascades, excite atoms in the topmost thin films. Radiation from deeper layers and substrate should be fairly suppressed.

In order to apply PIXE to analysis of selective sputtering of multicomponent surface, subjected to pro- 


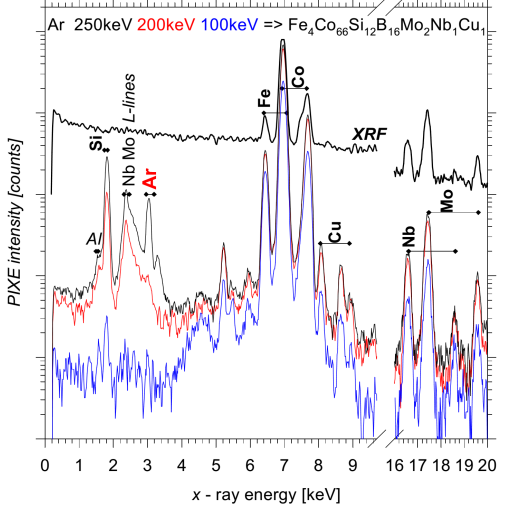

Fig. 1. PIXE spectra emitted from VV-6025X, irradiated with $250 / 200 / 100 \mathrm{keV}$ Ar ions and XRF spectrum induced by $122 \mathrm{keV} \gamma$-radiation from ${ }^{57} \mathrm{Co}$. SDD spectrometer, resolution $120 \mathrm{eV} / 6.4 \mathrm{keV}$.

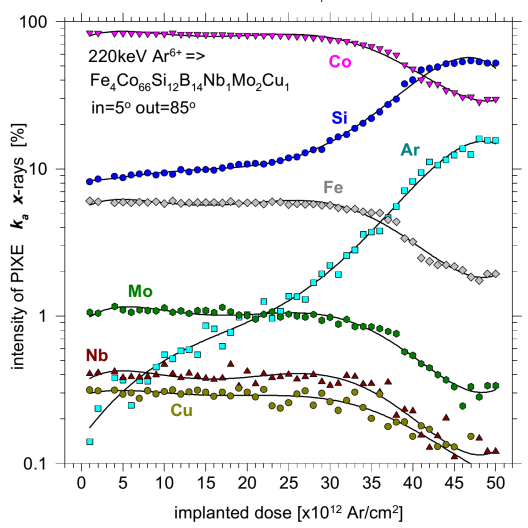

Fig. 2. Intensity of $\mathrm{k}_{\alpha} X$-rays from PIXE spectra, shown in Fig.(1), as functions of the implanted Ar dose.

longed irradiation with heavy ions, the characteristic $X$ ray spectra of elements contained in amorphous alloy $\mathrm{Fe}_{4} \mathrm{Co}_{66} \mathrm{Si}_{12} \mathrm{~B}_{14} \mathrm{Nb}_{1} \mathrm{Mo}_{2} \mathrm{Cu}_{1}$ were measured in time sequence. An example of raw spectra, induced by 100$250 \mathrm{keV} \mathrm{Ar}$ ions is shown in Fig. 1. $X$-ray lines are clearly shaped and the nominal initial composition can be confirmed with PIXE and XRF-FP package [9, 10]. Ghost lines are not marked in the figure. The corresponding penetration depth, at normal ion incidence, ranges from approximately $50 \mathrm{~nm}$ for $100 \mathrm{keV}$ Ar to $100 \mathrm{~nm}$ for $200 \mathrm{keV}$ Ar [11]. Normalization of the four spectra to Fe $\mathrm{k}_{\alpha}$ intensity enables us to see, that spectral structure remains constant (except for Ar peak). It can be seen that the dependence on energy is more important. The yield is much higher for $250 \mathrm{keV}$ ions, but the background is lower for $100 \mathrm{keV}$ ions, particularly at low $X$-ray energy.

Intensities of $\mathrm{k}_{\alpha} X$-rays from the surface elements, as functions of the dose of incident $220 \mathrm{keV}$ Ar ions, are shown in Fig. 2. Below $10^{13} \mathrm{Ar} / \mathrm{cm}^{2}$ there is a region of slow change of the PIXE intensity with Ar dose, and a region of rapid variation above this limit. Weaker PIXE signal from $\mathrm{Co}$ and stronger signal from $\mathrm{Si}$ can be interpreted as a result of preferential sputtering, which causes deficiency and abundance in the corresponding el- ements. The remaining elements, $\mathrm{Fe}, \mathrm{Nb}, \mathrm{Mo}$ and $\mathrm{Cu}$ give the PIXE yield which initially weakly depends on the implanted dose, however it subsequently decreases at higher doses. Calculation with SRIM [11] confirms, that $\mathrm{Cu}, \mathrm{Fe}$ and $\mathrm{Co}$ are sputtered at a higher rate, whereas $\mathrm{Si}, \mathrm{Mo}, \mathrm{Nb}$ and $\mathrm{B}$ are removed about twice less intensively. PIXE yield from Ar was increasing proportionally to implanted dose, and $5 \times 10^{13} \mathrm{Ar} / \mathrm{cm}^{2}$ in Fig. 2 corresponds to $0.05 \%$ concentration of Ar within the penetration depth of $100 \mathrm{~nm}$. Simultaneously, nearly $55 \%$ of incident Ar fluence is scattered out from the surface.

\section{Conclusions}

PIXE with $\mathrm{MeV}$ protons and helium ions is a reliable and well-established method of nondestructive elemental analysis of films and surfaces, supported by many codes which enable quantitative analysis without standards $[9,10]$.

PIXE produced by low energy heavy ions, despite of destructive effects, benefits from shallow penetration depth, larger $X$-ray production yield and better signal to background ratio. It can be shown that beam induced surface transformations such as: ion implantation, preferential sputtering and interface mixing can be quantitatively monitored with dose-dependent HI PIXE.

Such modification of surface and change of its elemental composition is essential for determining physical and chemical properties of the materials [12-14].

\section{References}

[1] M. Toulemonde, C. Dufour, E. Paumier, Phys Rev. B 46, 14362 (1992).

[2] M. Antoszewska, M. Wasiak, T. Gwizdałła, P. Sovak, M. Moneta, J. Therm. Anal Calorim. 115, 1381 (2014).

[3] G. Herzer, IEEE Transactions Magn. 26, 1397 (1990).

[4] M. Moneta, B. Pawłowski, Vacuum 78, 467 (2005).

[5] R. Brzozowski, M. Moneta, Nucl. Instr. Meth. Phys. Res. B 279, 208 (2012).

[6] S.A.E. Johansson, J.L. Campbell, K.G. Malmqvist, Particle Induced X-ray Emission spectrometry, WILEY 1995

[7] B. Pawłowski, M. Moneta, Nucl. Instr. Meth. Phys. Res. B 279, 194 (2012).

[8] E.Z. Frštczak, J.E. Prieto, M. Moneta, J. Alloys Com. 586, 375 (2014).

[9] http://www.amptek.com/.

[10] http://pixe.physics.uoguelph.ca/gupix/main/.

[11] J.F. Ziegler, J.P. Biersack, M.D. Ziegler, http://www . SRIM.org The Stopping and Range of Ions in Solids (2008).

[12] R. Brzozowski, M. Wasiak, H. Piekarski, P. Sovak, P. Uznaski, M. Moneta, J. Alloys Comp. 470, 5 (2009).

[13] M. Moneta, R. Brzozowski, M. Wasiak, P. Uznański, Nucl. Instr. Meth. Phys. Res. B 267, 411 (2009).

[14] M. Antoszewska, R. Brzozowski, J. Balcerski, K. Dolecki, E. Frątczak, B. Pawłowski, M. Moneta, Nucl. Instr. Meth. Phys. Res. B 310, 27 (2013). 